\title{
Philosophy of Music Education: Theoretical Growth Points of Chinese Localized Thoughts
}

\author{
Zhaoming Long \\ Jiangxi University of Technology, Nanchang, 330098, China
}

Keywords: philosophy of music education; localized thoughts; logical starting point

\begin{abstract}
Through establishing Chinese localized thoughts on philosophy of music education, this paper proposes that it is required to at least pay attention to theoretical growth from following 3 dimensions as for Chinese localized thoughts on philosophy of music education: firstly, it is required to deeply understand the connotation of Chinese traditional philosophy of music, and make clear what is Chinese music and what are characteristics of Chinese music; secondly, it is required to reasonably absorb the research results of western philosophy of music education (aesthetic philosophy of music education, practical philosophy of music education, and cultural philosophy of music education); thirdly, it is required to pay attention to the influence of new media environment on music education development. The research and discussion on these 3 aspects will become the logical starting point of current Chinese localized thoughts on philosophy of music education.
\end{abstract}

\section{Introduction}

The philosophy of music education refers to researching common phenomena and problems in music education through philosophical thoughts and concepts, or rising the common problems in music education to philosophical level. Hu Shi mentioned in An Outline of Philosophic History of China that "when we research problems closely related with our life, we shall seek for a fundamental solution from fundamental perspective, and this kind of knowledge is called philosophy". In recent years, Chinese scholars' discussion on philosophy concept of music education has been in the ascendant, and the research varies from introducing western mainstream philosophy concept of music education to discussing and developing western academic opinions on philosophy of music education; the influence is unprecedented and historic. However, the academic discussion and academic innovation on Chinese localized thoughts on philosophy of music education are very rare.

This paper proposes that it is required to at least pay attention to theoretical growth from 3 dimensions as for the localized thoughts on philosophy of music education: firstly, it is required to deeply understand the connotation of Chinese traditional philosophy of music, and make clear what is Chinese music and what are characteristics of Chinese music; secondly, it is required to reasonably absorb the research results of western philosophy of music education (aesthetic philosophy of music education, practical philosophy of music education, and cultural philosophy of music education); thirdly, it is required to pay attention to the influence of new media environment on music education development.

\section{Philosophical Connotation and Features of Chinese Traditional Music}

Chinese traditional philosophical thoughts realize great prosperity in the period of pre-Qin thinkers, and then they play an important role in the development of Chinese ancient society, including the influence on Chinese traditional music. Among pre-Qin thinkers, the most representative theories include Confucianism represented by Confucius and Mencius, Taoism represented by Zhuang-zi, Mohism represented by Mo Zhai, Legalists represented by Han Feizi, and strategics represented by Sun Pin and Guan Zhong, etc. Among those theories, the Confucianism, Taoism, and Mohism have the biggest influence on philosophical thoughts of Chinese traditional music.

1. Confucianism: thoughts of rites and music and beauty of harmony 
The thoughts of rites and music are one of important connotations in Confucianism; from Duke Zhou "formulating rites and music" to Confucius advocating "denying ourselves and returning to propriety", the important social function of rites and music is always emphasized. According to the history of King Wu's conquest over Shang Dynasty recorded in The Book of Music, it shows philosophical dialectical thoughts of music, and it also objectively emphasizes the philosophical dialectical relationship between "people" and "music" advocated in Confucianism, that is, people can make music prosperous, the music can also influence people, and "people" and "music" are interactive, which highlights the mutual dialectical relationship between subject and object.

Education function of rites and music: Among Six Arts ("rites, music, archery, chariot-riding, books, mathematics") in ancient China, the "rites" and "music" are ranked at the 1st and 2nd place respectively, thus we can see the important degree of rites and music education in ancient China. The poetry can express people's thoughts, ambition, and aspiration, and highlights the poetic thoughts; the song can extend people's thoughts, ambition, and aspiration included in poetry through singing; the sound shall conform to melody, and the melody shall be in harmony with five voices. The rites and music education is an important means for personality education, and it can also improve people's artistic appreciation. Confucius says: "as for a versatile person, he will become a perfect person if he is additionally taught with rites and music; people's cultivation starts from learning poetry, and then it is enhanced via learning rites, and finally it becomes perfect through learning music", which highly generalizes the important significance of rites and music education on fully perfecting personality.

Social function of rites and music: It is recorded in The Book of Music that "the music is the essence of virtue, and the rites are the order." It shows that the rites and music are regarded as the important means to administer state affairs well and ensure national security; the rites are the external control by order and level, and the music is internal edification on people's mood. The Confucianism pays great attention to the control function of "rites" and the cultivation function of "music". It is due to social function of rites and music that the strict rank order in ancient China is constructed, and the harmonious and stable social atmosphere is created, which provides sufficient condition for national long-term peace and order in terms of ideology. It is said in The Classic of Filial Piety that "the music is the best thing used to transform social traditions", which highly explains the moral education function of "music" on people and also explains that the music can make people inclined to goodness and reduce excessive appeal to gains.

The "harmony" spirit is a kind of group ideology formed in thousands of years of production and social practice by Chinese nation, and then it evolves into a kind of view of life and view of value, and it is reflected as beauty of harmony in Chinese traditional music. It is emphasized in Confucius's "there shall be moderate happiness or sadness" that the emotion shall be moderate; the concept of "complementing each other" proposed by Yan Yin is just the concept that all elements shall be harmonious and uniform; Shi Bo's "the harmony is the principle of creating things" and "combing with different things together to realize balance" propose that all elements of music shall be mutually compromised to realize supreme beauty of harmony. "From of old, Confucianism proposes "golden mean" to advocate "beauty of harmony" of music and makes it become a main aesthetic feature of Chinese traditional music."

2. Taoism: harmony between heaven and man, the tao way following nature, and beauty of reticence

Taoist philosophy is represented by Lao-zi and Zhuang-zi, and its core concept is "harmony between heaven and man, the tao way following nature", "any specific thing existing in the world will return to nothing, and then nothing derives all things", "existing" and "nothing", and "true" and "false"; Lao-zi's "existing and nothing" and "true and false" principle forms one of important features of Chinese traditional art (including Chinese painting and Chinese traditional music). The Taoist philosophical concept of "nothing" has been displayed in Chinese traditional art; furthermore, the features of "nothing" and "intangible" have become an important aesthetic category of Chinese traditional music and have continued up to now.

3. Mohism: thoughts of universal love, non-attack, and denunciation of music 
It is recorded in Huai Nan Tzu · Outline that "Mo Tzu learns Confucianism", thus it can be seen that Mohism is developed on the basis of Confucianism; however, on the basis of Confucianism, Mo Tzu made transformation and criticism, and Mohism became a "noted school of thought" which contended against Confucianism in the Warring States Period. Mohism advocates the thoughts of universal love, non-attack, and denunciation of music. Developed on the basis of Confucius's "benevolence" thought, the thought of "universal love" is the core thought of Mohism, and the thought of non-attack and denunciation of music is developed on the basis of thought of "universal love".

4. Features of Chinese traditional music

Chinese traditional music takes five-tone scale as basis, that is, Do, Re, Mi, Sol, La; through change on this basis, the six-tone and seven-tone scale are formed; western music takes the musical mode of mediaeval times as basis, and then the major and minor key system is gradually formed, and its scale basis is 7 tones. On the basis of rhythm system and musical form, Chinese traditional music also has its own features; different from western rhythm system and musical form, Chinese rhythm system is mainly a separate-rhythm system based on "two", while the western rhythm system is single-rhythm or composite-rhythm system based on "two" or "three". In terms of musical form, Chinese traditional music has relatively free structure, and it can form many forms of variations in impromptu performance; However, the western music, especially classical art music since Vienna classical music time, has strict structure, and the binary form, trilogy form, and sonata form all have different features.

\section{Introduction to Philosophical Thought of Western Mainstream Music Education}

\section{Aesthetic philosophy of music education}

"Since the end of 1950s, the appearance of two works (that is, Basic Concepts in Music Education (1958) and Foundations and Principles of Music Education (1959)) plays a key role in the formation process of philosophy of music education, and the work Foundations and Principles of Music Education is the sign of official appearance of music education, that is, aesthetic education." The representative of aesthetic philosophy of music education is American music educator Reimer who published the book A Philosophy of Music Education in 1970, which makes aesthetic music education reach a peak in America. The philosophical theory foundation of aesthetic music education comes from aesthetic concepts in works such as Susanne K. Langer's Feeling and Form and Leonard B. Meyer's Emotion and Meaning in Music.

The feature of aesthetic music education is to advocate the thought that "the music is aesthetic appreciation", the music education is emotional education, and the emotional education is aesthetic education; in a word, the music education is aesthetic education, and the highest value of music education is consistent with the highest value of aesthetic education. The appearance and flourishing of aesthetic music education have historic limitations; the dimension that the aesthetic music education pays attention to is aesthetic, but we ignore to review music from the dimension of society and culture. The music basis of aesthetic music education is European classical art music rather than world music. With development of subjects such as sociology and anthropology of music, the music is interpreted under the view of different subjects, and the change also happens in essence of music education accordingly.

2. Practical philosophy of music education

In the period from the end of 1980 s to the beginning of 1990 s, the aesthetic music education suffered more and more criticism and query, and the aesthetic creed it believed in also started to shake, especially "Special Research Interest Group" established in 1990 and "May Day Group" established on May 1, 1993 by American Music Educators National Conference, both of which devoted to thinking about goal of music education and music practice in a critical vision. The representative of practice philosophy of music education is David Elliott (America), and the appearance of his work Music Matters: A New Philosophy of Music Education shows the rising of practical philosophy of music education.

3. Cultural philosophy of music education 
Since $20^{\text {th }}$ century, with development and flourishing of anthropology of music, the music, as a kind of culture, is accepted and advocated by more and more scholars; in this way, the cultural philosophy of music education emerges at the right moment. The philosophical foundation of cultural music education is Martin Heidegger's existing hermeneutics and Gadamer's philosophical hermeneutics on the basis of existing hermeneutics; "his hermeneutics realizes the philosophical change of hermeneutics in terms of epistemology significance, that is, "understanding is basic form of existing". The hermeneutics is a philosophy of multiple dialogue, and it emphasizes interactive dialogue and mutual understanding between subjects.

\section{Influence of New Media Environment on Music Education Development}

Since this century, due to rapid development of information technology, the interactive way between people and people, between people and things, and between things and things becomes more convenient and multiple; as the medium of cultural communication, the media plays an important bridge and link role in cultural communication and development, as well as in musical communication and development, and the change also happens in music education accordingly. Therefore, the influence of new media environment on music education development is one of attention points as for Chinese localized thoughts on philosophy of music education.

1. Definition and features of new media

The new media refers to "media new technology", and "it generally refers to interactive digitalized composite media, mainly include internet (including mobile internet), commercial online service, CD-ROM catalogue and magazine, and independent computer kiosk and interactive TV, etc.". The new media environment is mainly characterized by following aspects: (1) appearance of We Media and whole people medium; (2) emerging of new virtual world and community space; (3) new publicity of network space. Especially under influence of new network technology, the maturity of mobile internet technology makes new media "shape our experience via different ways, and even determine the content to certain degree".

2. New media and music, music education

The music development can't be separated from development of media technology; from invention of music score to change of storage means and communication media, the technical development in media field always causes great influence on music development and music education. Faced with the impact of new media environment on music and music education, we must have deep thinking on music education status in new period. The change and influence of new media environment on music communication, music acceptance process, and music innovation are undisputed, and the appearance of new media environment also changes original expression and existing way of music. Various features shown by music determine features of music education, and it can be seen that the application of new media technology determines the features of music education. Therefore, the influence of new media environment on music and music education also determines that it becomes one of attention points as for Chinese localized thoughts on philosophy of music education.

\section{Conclusion}

Currently, the philosophy of music education shows a trend of pluralistic development; from aesthetic philosophy of music education and practical philosophy of music education to cultural philosophy of music education, it always reviews music education from perspective of aesthetics, sociology, and anthropology, and its purpose is to better serve for music education and serve for people. The logical starting point of Chinese localized thoughts on philosophy of music education must lay the roots in the philosophy of Chinese traditional music, reasonably absorb the advanced research results of philosophy of music education in current world, and practically pay attention to the important influence brought by new media environment on music education development. 


\section{References}

1. Wang Yaohua: Structural Features and Philosophical Foundation of Chinese Traditional Music, Hundred Schools in Arts [J], 2010.5

2. Chen Guoping: Aesthetic Interpretation on Chinese Traditional Music, Exploration and Free Views [J], 2005.8.

3. Qin Jiangmei: Aesthetic Paradigm and Practical Paradigm of Philosophy of Music Education, Chinese Music [J], 2008.1.

4. Guan Jianhua: Thoughts of Musical Culture Philosophy and Musical Teaching Philosophy, Journal of Xi' an Conservatory of Music [J], 2012.3.

5. Wang Liang: Power of Technology: Theoretical Growth Points of Music Education under New Media Environment, Education Science [J], 2013.8.

6. Liu Zhongwang: New Media Technology: Internet and Contemporary Lifestyle, Journal of Xiangtan University (Philosophy and Social Sciences), 2010.1. 